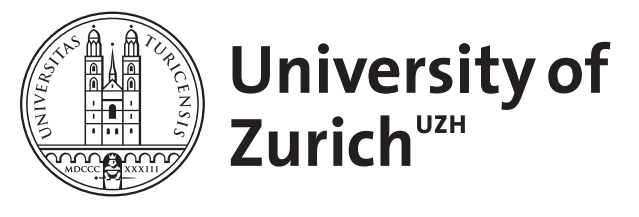

\title{
The hypoxic placenta
}

Tissot van Patot, Martha C ; Ebensperger, German ; Gassmann, Max ; Llanos, Aníbal J

\begin{abstract}
Hypoxia of the placenta is integral to complications of pregnancy, including preeclampsia, intrauterine growth restriction, and small-for-gestational age babies. Hypoxia in the placenta is associated with vascular remodeling, hypertension, metabolic changes, oxidative stress, mitochondrial dysfunction, and endoplasmic reticular stress. Hypoxia induces similar outcomes in other organs such as the lungs, kidney, and gut. Comparing and contrasting the effects of hypoxia on placental functions and functions of lung, kidney, and gut can lead to novel hypotheses and investigations, furthering our understanding of the impact of hypoxia on these diverse yet similar organs. In this review, we compare and contrast hypoxic placental responses to those in the other organ and cell systems.
\end{abstract}

DOI: https://doi.org/10.1089/ham.2012.1046

Posted at the Zurich Open Repository and Archive, University of Zurich ZORA URL: https://doi.org/10.5167/uzh-64889

Journal Article

Published Version

Originally published at:

Tissot van Patot, Martha C; Ebensperger, German; Gassmann, Max; Llanos, Aníbal J (2012). The hypoxic placenta. High Altitude Medicine and Biology, 13(3):176-184.

DOI: https://doi.org/10.1089/ham.2012.1046 


\title{
The Hypoxic Placenta
}

\author{
Martha C. Tissot van Patot, ${ }^{1}$ German Ebensperger, ${ }^{2,3}$ Max Gassmann, ${ }^{1,4}$ and Aníbal J. Llanos ${ }^{2,3}$
}

\begin{abstract}
Martha C. Tissot van Patot, Martha C., German Ebensperger, Max Gassmann, and Aníbal J. Llanos. The hypoxic placenta. High Alt Med Biol. 13:176-184, 2012. - Hypoxia of the placenta is integral to complications of pregnancy, including preeclampsia, intrauterine growth restriction, and small-for-gestational age babies. Hypoxia in the placenta is associated with vascular remodeling, hypertension, metabolic changes, oxidative stress, mitochondrial dysfunction, and endoplasmic reticular stress. Hypoxia induces similar outcomes in other organs such as the lungs, kidney, and gut. Comparing and contrasting the effects of hypoxia on placental functions and functions of lung, kidney, and gut can lead to novel hypotheses and investigations, furthering our understanding of the impact of hypoxia on these diverse yet similar organs. In this review, we compare and contrast hypoxic placental responses to those in the other organ and cell systems.
\end{abstract}

Key Words: preeclampsia; vascular remodeling; pulmonary hypertension; pulmonary vascular remodeling; oxidative stress; mitochondria; kidney; fetal hypoxia; gastrointestinal system

\section{Introduction}

$\mathbf{P}$ LACENTAl hypoxia is associated with impaired uterine invasion, poor villous development, loss of vascularity, reduced spiral artery remodeling, as well as complications of pregnancy including hypertension, preeclampsia, small-forgestational age neonates, and intrauterine growth restriction, among others. An increasing number of excellent reviews have focused on hypoxia-mediated placental responses (Charnock-Jones et al., 2004; Simon et al., 2008; Burton, 2009; Dunwoodie, 2009; Patel et al., 2010; Pringle et al., 2010; Burton et al., 2011; Tuuli et al., 2011). So what is new in the present review? As the placenta's response to reduced oxygenation mimics - at least to a given extent - the one found in several organs including lung, kidney, and gut, we compared the (patho-) physiological response of the latter organs to the placenta. Indeed, it was intriguing to observe that oxidative stress and downstream effects in placental cells are quite similar to other cells in the body, including the responses of different organelles such as mitochondria and endoplasmic reticulum (Burton et al., 2011). We are convinced that comparing placental hypoxia-mediated responses to those of other organ systems and cellular mechanisms will bring greater understanding of the mechanisms regulating the placenta's hypoxic response.

\section{Hypoxic Responses as in the Lung}

\section{Vascular remodeling}

Hypoxia causes pulmonary and uteroplacental arteries to have greater vasoconstrictive capabilities than during normoxia, and both vessels are associated with the development of hypertension. Note that the term 'vascular remodeling' has led to confusion, as it has different meanings depending as whether this term is used in pulmonary or placental areas of research. In pulmonary research, 'vascular remodeling' describes the pathophysiologic vascular changes induced by hypoxia, while in placental research it is used to describe physiologic changes during normoxic exposure. The impact of hypoxia on placental and pulmonary vasculature, however, is very similar.

There are two distinct circulations in the placenta, maternal and fetal. The maternal circulatory system undergoes remodeling or 'physiological conversion' during development. In a healthy pregnancy, as the placenta implants into the uteroplacental wall and oxygen tension increases with

\footnotetext{
${ }^{1}$ Institute of Veterinary Physiology, Vetsuisse Faculty and Zurich Center for Integrative Human Physiology (ZIHP), University of Zürich, Zürich, Switzerland.

${ }^{2}$ Unidad de Fisiología y Fisiopatología Perinatal (UFFP), Programa de Fisiopatología, Instituto de Ciencias Biomédicas (ICBM), Facultad de Medicina, Universidad de Chile, Santiago, Chile.

${ }^{3}$ International Center for Andean Studies (INCAS), Universidad de Chile, Santiago-Arica-Putre, Providencia, Santiago, Chile.

${ }^{4}$ Universidad Peruana Cayetano Heredia (UPCH), Lima, Peru.
} 
proximity to the uteroplacental arteries, the involved arteries are 'remodeled'. This means that originally muscularized and vasoreactive vessels become now dilated, nonmuscularized, and nonvasoreactive. This process insures sufficient blood flow to the placenta and in turn efficient oxygen and nutrient delivery to the fetus (Fig. 1).

When a placenta is exposed to lower $\mathrm{pO}_{2}$ during invasion, as occurs in residents at high altitude or in anemic patients, physiologic placental remodeling is impaired, resulting in the presence of more muscularized and vasoreactive vessels (Tissot van Patot et al., 2003; Cartwright et al., 2007). The process of physiologic remodeling in the placenta involves release of a variety of cytokines, matrix metalloproteinases, and growth factors by the placenta's decidual cells, thereby causing dilation of the vessels, followed by invasion of trophoblasts, specialized placental epithelial cells, and uterine natural killer cells (Harris, 2011). In a fully remodeled uteroplacental artery, nonvasoactive trophoblasts replace endothelial cells, and contractile smooth muscle cells are no longer present. In term placenta, endothelial cells can be found in some uteroplacental vessels of the basal plate, not only lining the artery but extending onto the inner surface of the basal plate (Ockleford, 2010). It is unclear if the uteroplacental arteries are re-endothelialized near term, thereby providing a means to reduce blood flow during placental delivery or if the vessels were never fully remodeled.

To come back to our analogy to the lung: many of the factors governing trophoblast invasion and uteroplacental remodeling are also involved in hypoxia-induced pulmonary vascular remodeling including, but not limited to, HIF alphas, VEGF, PlGF, IL-6, TGF $\beta$, and MAP kinases (Stenmark et al., 2006; Hanze et al., 2007; Knofler et al., 2011) (Table 1). Pulmonary vascular remodeling begins with hypoxia-induced

\section{Oxygen-mediated Vascular Remodeling}

\section{Placenta}
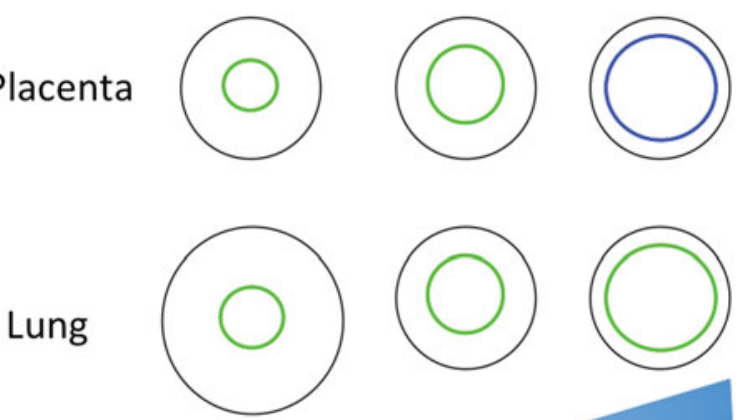

Oxygen

FIG. 1. The relationship of oxygen to vascular phenotype in placenta and lung is depicted. The relative values for low and high oxygen are related to the 'normoxic' oxygen for each organ, relatively low $\mathrm{pO}_{2}$ in the placenta and relatively high $\mathrm{PO} 2$ in the lung. Low oxygen in these organs yields vasoconstricted vessels, and the pulmonary system has a remodeled medial layer to be thickened primarily with smooth muscle cells. Higher oxygen concentrations yield dilated vessels in the placenta and lung, and at the maternoplacental interface endothelial cells are replaced by nonvasoreactive trophoblast. Green depicts endothelial cells, blue depicts trophoblasts. vasoconstriction, followed by medial and adventitial thickening. Increased vessel wall thickness can be attributed to the presence of an elevated number of smooth muscle cells, many of which are hypertrophied, and excessive collagen and elastin deposition (Stenmark et al., 2006) (Fig. 1).

\section{Hypertension}

Hypoxia is well known to result in hypertension in the pulmonary system and in the placental and maternal circulations. Notably, hypertension is prevalent in pregnancies at high altitude (Moore et al., 1982a; Palmer et al., 1994), leading a high altitude clinician to comment that "a pregnancy without high blood pressure is notable" (Lisa Zwerdlinger, M.D., Leadville, Colorado). Indeed, the placenta plays a key role in the development of maternal hypertension by releasing multiple vasoconstrictive factors, among those, reactive oxygen species (ROS), HIF- $1 \alpha$, lowered nitric oxide, increased sensitivity to angiotensin II, endothelin-1, and arachadonic acid metabolites such as thromboxane (Gilbert et al., 2008), all of which have also implicated in hypoxia-induced pulmonary hypertension (Sommer et al., 2008; Ward et al., 2009) (Table 1).

\section{Hypoxic Placenta Outcomes on Fetal/Neonatal Lung}

Because the placenta is ultimately responsible for the nurturing of the fetus, it is interesting in our analogy to consider what happens to the fetal pulmonary vascular system in response to placental hypoxia. Recently, Jayet et al. (2010) reported that children from preeclamptic pregnancies had $30 \%$ greater pulmonary vascular pressure than children from normotensive pregnancies. In support of these findings, it was found that the offspring of sheep exposed to high altitude during pregnancy have more muscularized pulmonary arteries and greater pulmonary vascular pressure than offspring from low altitude pregnancies (Llanos et al., 2011). Furthermore, pulmonary arteries demonstrated greater sensitivity to vasoconstrictors, $\mathrm{KCl}$, and endothelin-1, similar to the augmented responses of hypoxic placental and pulmonary vessels.

Taken together, the molecular and biochemical mechanisms involved in the hypoxic responses of placental and pulmonary vessels have extensive overlap. Detailed comparisons between the hypoxic responses of these organ systems deserve close scrutiny in lieu of the fact that the common final outcome, muscularized, hyperreactive, vasoconstrictive vessels, is associated with diseases that have high incidences of morbidity and mortality, such as preeclampsia and pulmonary hypertension. Indeed, the roles of RhoA and RhoA kinase (ROCK) in the hypoxic lung, but not placenta, have been extensively researched in recent years. It is now clear that the RhoA pathway plays a critical role in the pulmonary response to hypoxia (Ward et al., 2009). The few investigations in placenta demonstrate that RhoA/ROCK may be involved in trophoblast migration (Fafet et al., 2008; Nicola et al., 2008), but further investigations are necessary to clearly delineate the role of RhoA/ROCK in the hypoxic placenta.

Conversely, the TRAIL-FASL-mediated apoptotic pathway has been implicated in compromised placental vascular remodeling during hypoxia (Whitley et al., 2010), but not in hypoxia-mediated pulmonary vascular remodeling. Interestingly, TRAIL has been implicated in pulmonary fibroblast expression of TGF $\beta$ and collagen production (Yurovsky, 2003). These examples provide support for the value of 
Table 1. Molecular Pathways Involved in Placental and/or Pulmonary Vasoconstriction and Vascular Remodeling in Response to Hypoxia

\begin{tabular}{|c|c|c|c|}
\hline \multicolumn{2}{|c|}{ Location } & \multirow{2}{*}{$\begin{array}{c}\text { Vasoconstriction/ } \\
\text { Vascular Remodeling }\end{array}$} & \multirow[b]{2}{*}{ References } \\
\hline Placenta & Lung & & \\
\hline$X$ & $X$ & ROS & (Stenmark et al., 2006, Gilbert et al., 2008, Ward et al., 2009, Burton et al., 2011) \\
\hline$X$ & $X$ & $\mathrm{NO}$ & (Stenmark et al., 2006, Gilbert et al., 2008) \\
\hline$X$ & $X$ & ET-1 & (Stenmark et al., 2006, Gilbert et al., 2008) \\
\hline$X$ & $X$ & RhoA/ROCK & (Ward et al., 2009) \\
\hline$X$ & $X$ & Thromboxane & (Sommer et al., 2008, Gilbert et al., 2009, Ward et al., 2009) \\
\hline$X$ & $X$ & PI3K-AKT & (Gerasimovskaya et al., 2005, Park et al., 2010) \\
\hline$X$ & $X$ & Kv Channels & (Wareing et al., 2006, Sommer et al., 2008, Ward et al., 2009, Mistry et al., 2011) \\
\hline$X$ & $X$ & L-type $\mathrm{Ca}^{2+}$ Channels & (Jakoubek et al., 2006, Sommer et al., 2008) \\
\hline$X$ & $X$ & NADPH & (Sommer et al., 2008, Burton et al., 2011) \\
\hline$X$ & $X$ & $\mathrm{HIF}-1 \alpha$ & (Pak et al., 2007, Lee et al., 2010) \\
\hline$X$ & $X$ & VEGF & (Pak et al., 2007, Gilbert et al., 2008, Myatt et al., 2009) \\
\hline$X$ & $X$ & PLGF & (Pak et al., 2007, Gilbert et al., 2008, Myatt et al., 2009) \\
\hline$X$ & $X$ & IL-6 & (Bowen et al., 2005, Gilbert et al., 2008) \\
\hline$X$ & $X$ & Angiotensin & (Gilbert et al., 2008, Gonzalez et al., 2010) \\
\hline$X$ & $X$ & sFlt-1 & (Gilbert et al., 2008, Myatt et al., 2009) \\
\hline$X$ & $X$ & TGF $\beta$ & (Lee et al., 2010, Gong et al., 2011, Nasim et al., 2012) \\
\hline$X$ & $X$ & MAP kinases & (Pak et al., 2007, Harris 2011,, Nasim et al., 2012) \\
\hline$X$ & $X$ & TRAIL/FasL & (Whitley et al., 2010) \\
\hline$X$ & $X$ & MMPs & (Harris et al., 2010, Lee et al., 2010, Chelladurai et al., 2012) \\
\hline
\end{tabular}

References are primarily reviews discussing the role of the specific factor in the placenta or lung during hypoxia.

comparing and contrasting placental responses to hypoxia with responses of the pulmonary system.

\section{Hypoxic Responses as in the Kidney}

The hypoxic placenta produces factors usually considered the primary domain of the hypoxic kidney, including erythropoietin (Epo), angiotensin II, and adrenomedullin (ADM) (Conrad et al., 1996; Marinoni et al., 2007; LaMarca et al., 2011). For decades it was understood that hypoxia induces renal Epo production, thus stimulating erythropoiesis. In recent years, it has become clear that Epo has many functions other than stimulating the production of red blood cells. Nonerythroid functions include inhibition of apoptosis and stimulation of inflammatory and pro-angiogenic mechanisms in multiple organ systems, including the central nervous system, cardiovascular system, auditory system, retinal system, and the pancreas (Grimm et al., 2002; Gassmann et al., 2003; Chateauvieux et al., 2011). These nonerythroid actions of Epo serve to protect tissues from hypoxia and ischemic/ reperfusion injury (Mihov et al., 2009; Pappo et al., 2010).

In response to hypoxia, the placenta is also highly capable of Epo production, and has been reported to synthesize up to 20 times more Epo than the fetal kidney ( 0.44 vs. 0.18 million $\mathrm{mU}$ per hour) in an ovine model (Davis et al., 2003). Other than increasing fetal hemoglobin, nonhematopoietic Epo actions have the potential to positively or adversely affect placental and fetal development. For example, apoptosis is a key physiologic mechanism in normal fetal development and uteroplacental artery invasion and remodeling. Epo's proangiogenic actions might improve placental vascularity, thus elevating gas exchange between fetus and mother during hypoxia. Further, ischemic reperfusion injury (Burton et al., 2004) and elevated placental Epo concentrations (Teramo et al., 2004) have been associated with preeclampsia, a disease of pregnancy that involves reduced oxygen supply to this organ. Reports of Epo-mediated protection of ischemic reperfusion injury in heart and liver (Mihov et al., 2009; Pappo et al., 2010) suggest that elevated placental Epo production may be of benefit in preeclampsia.

\section{Adaptation of highlanders}

In the kidney, hypoxia-induced Epo production is primarily mediated by hypoxia inducible factor -2 (HIF-2) (Rankin et al., 2007). In the placenta, hypoxia led to greater accumulation of HIF- $2 \alpha$ but not of HIF- $1 \alpha$ (Genbacev et al., 2001, Tissot van Patot et al., 2004). Interestingly, polymorphisms of EPAS1, the gene encoding HIF-2, were recently reported in Tibetans highly adapted to residence at extreme altitudes. These polymorphisms were highly associated with low hemoglobin concentration in the Tibetan population (reviewed in Tissot van Patot et al., 2011). In other words: the kidney likely has less HIF-2/Epo expression in this adapted population. Tibetans also experience a much lower incidence of preeclampsia and low birth weight at high altitude, compared with the Han population, who represent Chinese native to low altitude (Julian et al., 2009). Placental function is intimately involved in the development of preeclampsia and birth weight, and Epo is implicated in the development of preeclampsia and reduction of body weight (Katz et al., 2010). It is quite possible that the EPAS1 adaptation extends to placentas from healthy, but not preeclamptic or low birth weight, pregnancies at high altitude.

EGLN1 is the gene encoding prolyl hydroxylase 2 (PHD2) that in turn inhibits the $\alpha$ subunits of HIFs by targeting them for ubiquination. PHD2 is specific for inhibition of Epo production in kidney (Minamishima et al., 2010). Severe placental defects in PHD2-deficient mice result in highly elevated HIF concentrations and embryonic lethality between E12.5-E14.5 (Takeda et al., 2006). Interestingly, a mutation of the EGLN1 gene is reported in Andean populations (Peng et al., 2011) 
who are well adapted to high altitude and-unlike the Tibetans-Andeans such as Quechuas and Aymaras have high hemoglobin concentrations (Beall et al., 1998). These data suggest that the EGLN1 mutation lowers PHD2, leading to elevated renal production of HIF2 and Epo. Accordingly, Andeans do not demonstrate the mutation in the EPAS1 gene that is present in Tibetans (Beall et al., 2010).

In summary, genomic analyses suggest that Tibetans have adapted to altitude by mutating EPAS1, reducing HIF-2, Epo, and hemoglobin concentrations, while Andeans have adapted by mutating PHD2, increasing HIF-2, Epo, and hemoglobin concentrations. Such variability in placental Epo concentrations would result in greatly differing placental morphology and functions between these adapted populations. Further studies are urgently needed to discover how such differing genetic mutations can each result in successful adaptations and pregnancies in high altitude native populations.

\section{Impact on blood pressure}

Hypoxia not only increases renal and placental Epo production, but hypoxia or Epo alone induces activity of the renin-angiotensin system (RAS) in a variety of ways. The RAS increases blood pressure directly via receptors in the vascular system and indirectly by increasing blood volume via retention of sodium in the kidney. In the placenta, Epo increases vasoconstriction via the angiotensin I (AT1) receptor primarily in placental veins delivering blood to the fetus (Resch et al., 2003). Placental hypoxia increases angiotensin II production (Knock et al., 1994), activity of angiotensin converting enzyme (ACE) (Ito et al., 2002), and AT1 receptor agonist autoantibodies (Wallukat et al., 1999), all of which are elevated in preeclamptic placentas (Herse et al., 2008). Activation of angiotensin receptors in the placenta increase vasoconstriction of veins delivering blood to the fetus (Resch et al., 2003), decreases trophoblast differentiation and invasion (Araki-Taguchi et al., 2008), increases reactive oxygen species (ROS) via NADPH oxidase and increases $\mathrm{NF} \kappa \mathrm{B}$ and thus inflammation (Dechend et al., 2003) , all of which are implicated in preeclampsia.

In the kidney, hypoxia and/or Epo stimulate an increase in angiotensin II, which in turn leads to an increase in systemic blood pressure. As in the hypoxic placenta, angiotensin II can also cause cellular damage by initiating oxidative stress (Palm et al., 2011). Thus, the RAS has been implicated in the development of renal allograft rejection, renovascular disease, and malignant hypertension. Interestingly, AT1 receptor agonist autoantibodies are elevated in these conditions and blocking receptor binding can reduce blood pressure and kidney damage (LaMarca et al., 2011). Angiotensin II blockade or ACE inhibition can also reduce blood pressure and kidney damage (Lebel et al., 2006), however the hematocrit also falls in patients treated this way (Qureshi et al., 2007). Delivery of ACE inhibitors during pregnancy is not advised due to increased risk of major congenital malformations (first trimester) and elevated risk of fetopathies (second and third trimesters) (Cooper et al., 2006).

As expected by the highly variable data from hypoxic kidneys cited above, epidemiologic studies of kidney function at high altitude have variable results. Some studies show altitude residents having a greater disposition toward a syndrome referred to as high altitude renal syndrome (Arestegui et al., 2011) and development of chronic kidney disease (Chen et al., 2011), while others demonstrate a beneficial effect of altitude by decreased mortality in dialysis patients (Winkelmayer et al., 2009) and a protective effect in chronic kidney disease patients (Ghahramani et al., 2011). The kidney and placenta play important roles in control of blood pressure in response to hypoxia. However, the hypoxic responses also cause damage to the cells and organ systems. The similarities between these two organ systems in their mechanisms of hypoxic response go far beyond those that are highlighted here and include nitric oxide, generation of reactive oxygen species, and changes in mitochondrial function. The resulting hypertension and end organ dysfunction have high rates of mortality and there is great potential for similar therapeutic interventions to work on both organ systems.

\section{Hypoxic Responses as in the Gut}

Placental function mimics gut function by selectively delivering nutrients from the maternal circulation to the fetus. Hypobaric hypoxia results in lower birth weight (Lichty et al., 1957; Moore et al., 1982b) and loss of weight in response in adults (Westerterp et al.,1992; Lippl et al., 2010). Unfortunately, present data regarding placental expression of glucose transporter 1 (GLUT1) during hypoxia are variable and inconclusive (Hayashi et al., 2004; Zamudio et al., 2010). It is likely that the reduction in fetal glucose concentrations at high altitude, associated with lower birth weight, is due to a combination of factors. Moore et al. (2011) have demonstrated significant altitude-associated reduction in uterine artery blood flow, thus delivering less glucose to the placenta and fetus, while Zamudio et al. (2010) suggest that the placenta increases glucose uptake, thus 'robbing' the fetus of glucose at high altitude. Recent metabolomics data, however, do not reveal direct evidence of greater placental glycolysis in high as compared to low altitude placentas, yet altitude placentas did demonstrate a tendency toward storing energy in the form of phosphocreatine (Tissot van Patot et al., 2010). Furthermore, placental hormonal factors, including leptin and ghrelin, are associated with low birth weight in preeclampsia (Aydin et al., 2008) at high altitude (Trollmann et al., 2007).

Similar to the reduction in birth weight when pregnancy occurs at high altitude, ascent to altitude in human subjects results in reduced body weight. The mechanism of weight loss at altitude remains unknown, yet gastrointestinal blood flow does not appear to be a factor (Kalson et al., 2010), while the roles of leptin and ghrelin are disputed (Quintero et al., 2010; Aeberli et al., 2012). These authors discuss additional mechanisms of hypoxia-induced weight loss that have been implicated, including loss of appetite, poor nutrient absorption, and inflammation (Quintero et al., 2010), some of which deserve investigation in the phenomenon of low birth weight at high altitude.

\section{The Common Denominator: Oxidative Stress}

Hypoxia results in oxidative stress, generation of reactive oxygen species (ROS), and initiation of multiple molecular cascades, resulting in a myriad of biological outcomes, including hypertension, vascular remodeling, erythropoiesis, angiogenesis, glycolysis, and many others. ROS can activate physiologic processes to protect cells from hypoxia as well as pathologic process that damage organs. These molecular cascades initiated by ROS include activation of a variety of transcription factors and protein kinases, opening ion chan- 
nels, protein modifications, lipid peroxidation, and DNA oxidation (Burton et al., 2011). In pathological conditions, ROSinitiated pathways can lead to vascular remodeling, hypertension, altered cellular differentiation or proliferation, impaired cellular transport, reduced enzyme kinetics, and many more. Chronic exposure to ROS impacts the placenta and is involved in the development of intrauterine growth restriction, preeclampsia, and spontaneous miscarriage (Burton et al., 2011), largely by impairing uteroplacental artery remodeling, uterine invasion, and vascular development. Similarly, the effects of ROS on pulmonary, renal, and gastrointestinal systems can contribute to the development of pulmonary hypertension, chronic kidney disease, and inflammatory bowel disease.

Mitochondria generate ROS during hypoxia, which in turn mediate cellular response to hypoxia (Hamanaka et al., 2010). The complexity of the system and overlap in function is extreme. For example, mitochondrial ROS activate stabilization of hypoxia-inducible transcription factors (HIFs) (Fandrey et al., 2006) and HIFs mediate mitochondrial respiration during hypoxia (Chandel et al., 2000). There is also a close relationship between oxidative stress, mitochondrial response, and the endoplasmic reticulum (ER). Because protein metabolism is responsible for about $30 \%$ of cellular oxygen consumption, it is vital for the ER to communicate with the mitochondria during hypoxic stress (Burton et al., 2011). In the placenta, it was recently reported that hypobaric hypoxia created ER stress, activating the unfolded protein response, thus modulating protein synthesis in placentas, possibly contributing to the reduced villous volume in high altitude placentas and the resultant lower birth weight (Yung et al., 2012). Hypoxic activation of the unfolded protein response in endoplasmic reticulum has also been reported in hypoxic kidneys (Inagi, 2010) and endothelium (Bouvier et al., 2009).

\section{Translational science: How does the hypoxic placenta affect the fetus?}

When hypoxia creates pathologies in the lungs, kidney, and gut, the patient suffers illness and disease. When hypoxia

Table 2. pH and Arterial Blood Gases in Ascending Aorta in Fetal Sheep Basally and During ACUTE Hypoxia

\begin{tabular}{|c|c|c|c|c|}
\hline & & Basal & Hypoxemia & Recovery \\
\hline $\mathrm{pH}$ & $\begin{array}{l}\text { LALA } \\
\text { LAHA }\end{array}$ & $\begin{array}{l}7.385 \pm 0.010 \# \\
7.425 \pm 0.017^{*}\end{array}$ & $\begin{array}{l}7.325 \pm 0.022 \\
7.400 \pm 0.006\end{array}$ & $\begin{array}{l}7.317 \pm 0.019 \\
7.400 \pm 0.013^{*}\end{array}$ \\
\hline $\begin{array}{l}\mathrm{pCo}_{2} \\
\mathrm{mmHg}\end{array}$ & $\begin{array}{l}\text { LALA } \\
\text { LAHA }\end{array}$ & $\begin{array}{l}45.6 \pm 1.0 \\
43.2 \pm 1.4\end{array}$ & $\begin{array}{l}43.7 \pm 1.3 \\
40.7 \pm 1.0\end{array}$ & $\begin{array}{l}43.4 \pm 1.2 \\
38.8 \pm 1.6^{* \dagger}\end{array}$ \\
\hline $\begin{array}{l}\mathrm{pO}_{2} \\
\mathrm{~mm} \mathrm{Hg}\end{array}$ & $\begin{array}{l}\text { LALA } \\
\text { LAHA }\end{array}$ & $\begin{array}{l}21.0 \pm 0.8 \\
14.5 \pm 1.2^{*}\end{array}$ & $\begin{array}{l}12.6 \pm 0.4 \# \\
11.2 \pm 1.0 \#\end{array}$ & $\begin{array}{l}21.5 \pm 0.9 \\
15.0 \pm 1.3^{*}\end{array}$ \\
\hline $\begin{array}{l}\mathrm{Hb} \\
\mathrm{g} / \mathrm{dL}\end{array}$ & $\begin{array}{l}\text { LALA } \\
\text { LAHA }\end{array}$ & $\begin{array}{l}10.0 \pm 0.3 \\
11.6 \pm 0.7^{*}\end{array}$ & $\begin{array}{l}10.3 \pm 0.4 \\
11.7 \pm 0.7^{*}\end{array}$ & $\begin{array}{r}9.7 \pm 0.5 \# \\
11.3 \pm 0.7^{*}\end{array}$ \\
\hline satHb\% & $\begin{array}{l}\text { LALA } \\
\text { LAHA }\end{array}$ & $\begin{array}{l}56.2 \pm 1.6 \\
41.4 \pm 6.3^{*}\end{array}$ & $\begin{array}{l}25.5 \pm 2.3 \# \\
25.5 \pm 4.7^{* \#}\end{array}$ & $\begin{array}{l}50.8 \pm 2.8 \\
37.9 \pm 5.3^{*}\end{array}$ \\
\hline $\begin{array}{l}\mathrm{O}_{2} \text { cont } \\
\mathrm{mlO}_{2} / \mathrm{dL}\end{array}$ & $\begin{array}{l}\text { LALA } \\
\text { LAHA }\end{array}$ & $\begin{array}{l}7.6 \pm 0.1 \\
6.4 \pm 0.6\end{array}$ & $\begin{array}{l}3.6 \pm 0.3 \# \\
4.0 \pm 0.5 \#\end{array}$ & $\begin{array}{l}6.7 \pm 0.4 \\
5.9 \pm 0.4\end{array}$ \\
\hline
\end{tabular}

Values are means \pm SEM taken at 15 and $45 \mathrm{~min}$ of basal, each $15 \mathrm{~min}$ during hypoxemia, and 15 and $45 \mathrm{~min}$ of recovery. Significant differences $(p \leq 0.05)$.

$\dagger$, vs. basal period; \#, vs. all periods in the same experimental group; *, vs. LALA fetuses. creates pathophysiology in the placenta, the fetus may suffer developmental pathologies. It has recently been reported that children from preeclamptic pregnancies at high altitude have elevated pulmonary artery pressures (Jayet et al., 2010). Similarly, we have reported elevated pulmonary artery pressures and differences in responses to vasoactive substances in an ovine offspring from high altitude pregnancies (Herrera et al., 2010; Llanos et al., 2011; Moraga et al., 2011). These data strongly suggest that a hypoxic placenta produces long-lasting changes in fetal physiology.

We have recently extended these studies to the cardiovascular system, hypothesizing that the cardiovascular basal status and cardiovascular defense responses to acute hypoxia in lowland fetal sheep grown at high altitude are blunted in comparison to fetuses that underwent gestation at sea level. Using a protocol similar to that previously reported (Herrera et al., 2010; Moraga et al., 2011), we studied fetal at day 130 of gestation (87\% gestation) at 580 meters above sea level (LALA) and fetal sheep from lowland taken to 3600 meters above sea level at $45-50$ days of gestation (30\% gestation) (LAHA). To summarize our findings, in fetuses whose gestation took place partially in chronic hypoxia (LAHA) we found that:

1. Three out of 7 LAHA fetuses died in utero prior to the age of catheterization and there was marked fetal
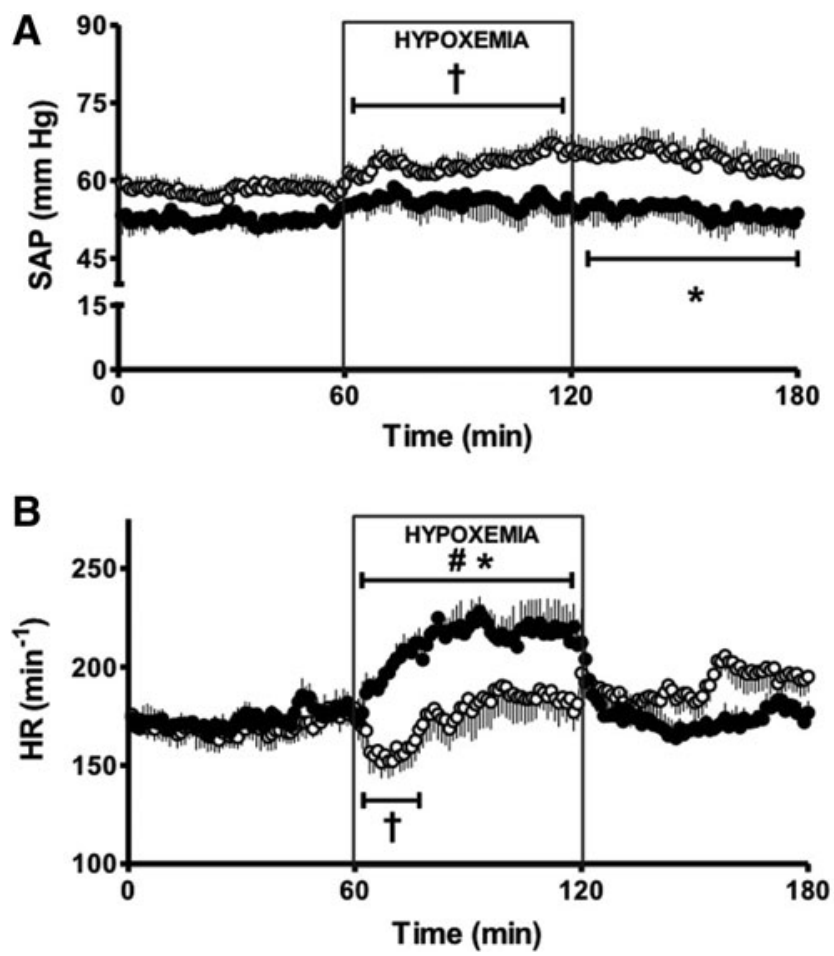

FIG. 2. Mean systemic arterial pressure (SAP; Panel A) and heart rate (HR; Panel B) in sheep fetuses whose conception and $87 \%$ of pregnancy took placed at low altitude (LALA; open circles) and sheep fetuses whose conception took placed at low altitude and pregnancy at high altitude $(3600 \mathrm{~m})$, from $30 \%$ of gestation until $87 \%$ of gestation (LAHA; closed circles). Values are means \pm SEM. Significant differences $(p<0.05)$ are as follows: SAP; Panel A: $\dagger$ LALA fetuses vs. Basal period; ${ }^{*}$, LAHA vs. LALA fetuses; HR; Panel B: $\dagger$ LALA fetuses $v s$. Basal period; *, LALA vs. LAHA fetuses; \#, LAHA fetuses $v s$. all periods in the same experimental group. 
growth retardation. In contrast, all the sea level pregnancies (LALA) had 100\% survival. The striking decrease in $\mathrm{PO}_{2}$ in LAHA fetal sheep can explain the marked fetal growth restriction and mortality in these fetuses (Table 2).

2. No bradycardia was seen as response to hypoxia. In contrast, there was an increased heart rate, evidencing an absent chemoreflex with a diminished vagal response plus an augmented sympathetic outcome (Fig. 2).

3. Basally, there was an increased carotid blood flow, as the result of the low $\mathrm{PO}_{2}$ in the arteries supplying the central nervous system, probably due to an increased NO production, among other mediators (Fig. 3).

4. The systemic arterial pressure and carotid blood flow showed blunted responses to acute hypoxemia, responses observed even during the recovery period (Figs. 2 and 3).

We speculate that the observed blunting in the cardiovascular responses in chronically hypoxic fetuses reflects the expression of a hypometabolic state in the tissues, fingering the main regulation at cellular and tissue levels with little need of major cardiovascular adjustments to cope with acute changes in $\mathrm{PO}_{2}$.

These data support the hypothesis that a hypoxic placenta can have a strong influence on the health of the fetus, similar

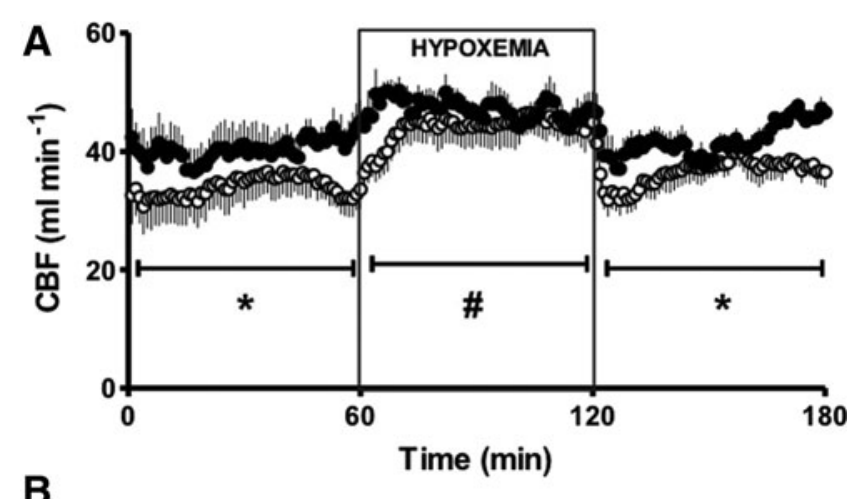

B

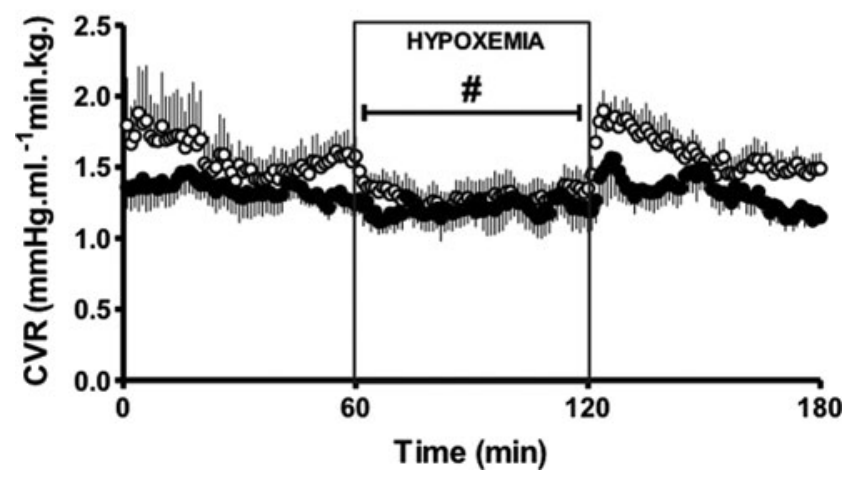

FIG. 3. Carotid blood flow (CBF; Panel A) and carotid vascular resistance (CVR; Panel B) in sheep fetuses whose conception and $87 \%$ of pregnancy took placed at low altitude (LALA; open circles) and sheep fetuses whose conception took placed at low altitude and pregnancy at high altitude $(3600 \mathrm{~m})$, from $30 \%$ of gestation until $87 \%$ of gestation (LAHA; closed circles). Values are means \pm SEM. Significant differences $(p<0.05)$ are as follows: CBF; Panel A: ${ }^{*}$, LALA vs. LAHA fetuses; \#, LALA fetuses vs. all periods in the same experimental group; CVR; Panel B: \#, LALA fetuses vs. all periods in the same experimental group. to the way in which hypoxic organs negatively impact the health of the individual.

\section{Conclusion}

In its role of supporting fetal development, the placenta must fulfill the actions of many physiologic processes, including the delivery of oxygen and nutrients, removal of waste products, blood pressure control, and hormone production. Hypoxia stresses the placenta's ability to perform these functions in a manner similar to hypoxia-induced stress created in other organs responsible for similar functions such as the lungs, gut, and kidneys. Furthermore, at the cellular level, hypoxia-induced oxidative stress activates similar cascades in trophoblast and vascular endothelial cells, smooth muscle cells, and fibroblasts in multiple organ types. Comparing and contrasting these molecular cascades and the resulting hypoxia-induced pathophysiologies in various organ systems will likely stimulate further investigations into the etiology and outcome of placental hypoxia, leading to a greater understanding of placental-mediated diseases.

\section{Author Disclosure Statement}

No competing financial interests exist.

Part of this work was funded by the grant FONDECYT 1090355, Chile.

\section{References}

Aeberli I, Erb A, Spliethoff K, Meier D, Götze O, Frühauf H, Fox H, Finlayson GH, Gassmann M, Maggiorini M, Langhans L, and Lutz TA. (2012). Disturbed eating at high altitude: Influence of food preferences, acute mountain sickness and satiation hormones. Eur J Nutrit In Press.

Araki-Taguchi M, Nomura S, Ino K, Sumigama S, Yamamoto E, Kotani-Ito T, Hayakawa H, Kajiyama H, Shibata K, Itakura A, and Kikkawa F. (2008). Angiotensin II mimics the hypoxic effect on regulating trophoblast proliferation and differentiation in human placental explant cultures. Life Sci 82:59-67.

Arestegui AH, Fuquay R, Sirota J, Swenson ER, Schoene RB, Jefferson JA, Chen W, Yu X-Q, Kelly JP, Johnson RJ, and Escudero E. (2011). High altitude renal syndrome (HARS). J Am Soc Nephrol 22:1963-1968.

Aydin S, Guzel SP, Kumru S, Aydin S, Akin O, Kavak E, Sahin I, Bozkurt M, and Halifeoglu I. (2008). Serum leptin and ghrelin concentrations of maternal serum, arterial and venous cord blood in healthy and preeclamptic pregnant women. J Physiol Biochem 64:51-59.

Beall C, Cavalleri G, Deng L, Elston R, Gao Y, Knight J, Li C, Li J, Liang Y, and McCormack M. (2010). Natural selection on EPAS1 (HIF2 ) associated with low hemoglobin concentration in Tibetan highlanders. Proc Natl Acad Sci US 107:1145911464 .

Beall CM, Brittenham GM, Strohl KP, Blangero J, WilliamsBlangero S, Goldstein MC, Decker MJ, Vargas E, Villena M, Soria R, Alarcon AM, and Gonzales C. (1998). Hemoglobin concentration of high-altitude Tibetans and Bolivian Aymara.[Erratum appears in Am J Phys Anthropol 1998 Dec;107:421]. Am J Phys Anthropol 106:385-400.

Bouvier N, Flinois JP, Gilleron J, Sauvage F-L, Legendre C, Beaune P, Thervet E, Anglicheau D, and Pallet N. (2009). Cyclosporine triggers endoplasmic reticulum stress in endothelial cells: A role for endothelial phenotypic changes and death. Am J Physiol Renal Physiol 296:F160-169. 
Burton GJ. (2009). Oxygen, the Janus gas; its effects on human placental development and function. J Anat 215:27-35.

Burton GJ and Jauniaux E. (2004). Placental oxidative stress: From miscarriage to preeclampsia. J Soc Gynecol Invest 11:342-352.

Burton GJ and Jauniaux E. (2011). Oxidative stress. Best Practice Res ClinObstet Gynaecol 25:287-299.

Cartwright J, Keogh CL, and Tissot van Patot MC. (2007). Hypoxia and placental remodeling. Adv Exper Med Biol 618:113126.

Chandel NS, McClintock DS, and Feliciano CE. (2000). Reactive oxygen species generated at mitochondrial complex III stabilize hypoxia-inducible factor-1alpha during hypoxia: A mechanism of O2 sensing. J Biol Chem 275:25130-25138.

Charnock-Jones DS, Kaufmann P, and Mayhew TM. (2004). Aspects of human fetoplacental vasculogenesis and angiogenesis. I. Molecular regulation. Placenta 25:103-113.

Chateauvieux S, Grigorakaki C, Morceau F, Dicato M, and Diederich M. (2011). Erythropoietin, erythropoiesis and beyond. Biochem Pharmacol 82:1291-1303.

Chen W, Liu Q, Wang H, Chen W, Johnson RJ, Dong X, Li H, Ba S, Tan J, Luo N, Liu T, He H. and Yu X. (2011). Prevalence and risk factors of chronic kidney disease: A population study in the Tibetan population. Nephrol Dialysis Transplant 26:15921599.

Conrad KP, Benyo DF, Westerhausen-Larsen A, and Miles TM. (1996). Expression of erythropoietin by the human placenta. FASEB J 10:760-768.

Cooper WO, Hernandez-Diaz S, Arbogast PG, Dudley JA, Dyer S, Gideon PS, Hall K, and Ray WA. (2006). Major congenital malformations after first-trimester exposure to ACE inhibitors. New Eng J Med 354:2443-2451.

Davis LE, Widness JA, and Brace RA. (2003). Renal and placental secretion of erythropoietin during anemia or hypoxia in the ovine fetus. Am J Obstet Gynecol 189:1764-1770.

Dechend R, Viedt C, Muller DN, Ugele B, Brandes RP, Wallukat G, Park J-K, Janke J, Barta P, Theuer J, Fiebeler A, Homuth V, Dietz R, Haller H, Kreuzer J, and Luft FC. (2003). AT1 receptor agonistic antibodies from preeclamptic patients stimulate NADPH oxidase. Circulation 107:1632-1639.

Dunwoodie SL. (2009). The role of hypoxia in development of the mammalian embryo. Develop Cell 17:755-773.

Fafet P, Rebouissou C, Maudelonde T, and Vignais ML. (2008). Opposite effects of transforming growth factor-beta activation and rho-associated kinase inhibition on human trophoblast migration in a reconstituted placental-endometrial coculture system. Endocrinology 149:4475-4485.

Fandrey J, Gorr TA, and Gassmann M. (2006). Regulating cellular oxygen sensing by hydroxylation. Cardiovasc Res 71:642-651.

Gassmann M, Heinicke K, Soliz J, and Ogunshola OO. (2003). Non-erythroid functions of erythropoietin. Adv Exp Med Biol 543:323-330.

Genbacev O, Krtolica A, Kaelin W, and Fisher SJ. (2001). Human cytotrophoblast expression of the von Hippel-Lindau protein is downregulated during uterine invasion in situ and upregulated by hypoxia in vitro. Develop Biol 233:526-536.

Ghahramani N, Ahmed F, Al-Laham A, and Lengerich EJ. (2011). The epidemiological association of altitude with chronic kidney disease: Evidence of protective effect. Nephrology 16:219-224.

Gilbert JS, Ryan MJ, LaMarca BB, Sedeek M, Murphy SR, and Granger JP. (2008). Pathophysiology of hypertension during preeclampsia: Linking placental ischemia with endothelial dysfunction. Am J Physiol Heart Circ Physiol 294:H541-H550.
Grimm C, Wenzel A, Groszer M, Mayser H, Seeliger M, Samardzija M, Bauer C, Gassmann M, and Remé CE. (2002). HIF-1-induced erythropoietin in the hypoxic retina protects against light-induced retinal degeneration. Nature Med 8:718724.

Hamanaka RB and Chandel NS. (2010). Mitochondrial reactive oxygen species regulate cellular signaling and dictate biological outcomes. Trends Biochem Sci 35:505-513.

Hanze J, Weissmann N, Grimminger F, Seeger W, and Rose F. (2007). Cellular and molecular mechanisms of hypoxia-inducible factor driven vascular remodeling. Thromb Haemostasis 97:774-787.

Harris LK. (2011). IFPA Gabor Than Award lecture: Transformation of the spiral arteries in human pregnancy: Key events in the remodelling timeline. Placenta 32:S154-158.

Hayashi M, Sakata M, Takeda T, Yamamoto T, Okamoto Y, Sawada K, Kimura A, Minekawa R, Tahara M, Tasaka K, and Murata Y. (2004). Induction of glucose transporter 1 expression through hypoxia-inducible factor 1alpha under hypoxic conditions in trophoblast-derived cells. J Endocrinol 183:145154.

Herrera EA, Riquelme RA, Ebensperger G, Reyes RV, Ulloa CE, Cabello G, Krause BJ, Parer JT, Giussani DA, and Llanos AJ. (2010). Long-term exposure to high-altitude chronic hypoxia during gestation induces neonatal pulmonary hypertension at sea level. Am J Physiol Regul Integr Comp Physiol 299:R16761684.

Herse F, Staff AC, Hering L, Muller DN, Luft FC, and Dechend R. (2008). AT1-receptor autoantibodies and uteroplacental RAS in pregnancy and pre-eclampsia. J Mol Med 86:697-703.

Inagi R. (2010). Endoplasmic reticulum stress as a progression factor for kidney injury. Curr Opin Pharmacol 10:156-165.

Ito M, Itakura A, Ohno Y, Nomura M, Senga T, Nagasaka T, and Mizutani S. (2002). Possible activation of the renin-angiotensin system in the feto-placental unit in preeclampsia. J ClinEndocrinol Metab 87:1871-1878.

Jayet P-Y, Rimoldi SF, Stuber T, Salmon CS, Hutter D, Rexhaj E, Thalmann S, Schwab M, Turini P, Sartori-Cucchia C, Nicod P, Villena M, Allemann Y, Scherrer U, and Sartori C. (2010). Pulmonary and systemic vascular dysfunction in young offspring of mothers with preeclampsia. Circulation 122:488494.

Julian CG, Wilson MJ, and Moore LG. (2009). Evolutionary adaptation to high altitude: A view from in utero. Ame J Human Biol 21:614-622.

Kalson NS, Hext F, Davies AJ, Chan CWM, Wright AD, Imray $\mathrm{CHE}$, and Birmingham Medical Research Expeditionary, S. (2010). Do changes in gastro-intestinal blood flow explain high-altitude anorexia? Eur J Clin Invest 40:735-741.

Katz O, Stuible M, Golishevski N, Lifshitz L, Tremblay ML, Gassmann M, Mittelman M, and Neumann D. (2010). Erythropoietin treatment leads to reduced blood glucose levels and body mass: Insights from murine models. J Endocrinol 205:87-95.

Knock GA, Sullivan MHF, McCarthy A, Elder MG, Polak JM, and Wharton J. (1994). Angiotensin II (AT1) vascular binding sites in human placenta from normal-term, preeclamptic and growth retarded pregnancies. J Pharmacol ExpTherapeut 271:1007-1015.

Knofler M and Pollheimer J. (2011). IFPA Award in Placentology Lecture: Molecular regulation of human trophoblast invasion. Placenta 33: S55-S62.

LaMarca B, Wallace K, and Granger J. (2011). Role of angiotensin II type I receptor agonistic autoantibodies (AT1-AA) in preeclampsia. Curr Opin Pharmacol 11:175-179. 
Lebel M, Rodrigue M-E, Agharazii M, and Lariviere R. (2006). Antihypertensive and renal protective effects of reninangiotensin system blockade in uremic rats treated with erythropoietin. Am J Hyperten 19:1286-1292.

Lichty JA, Ting RY, Bruns PD, and Dyar E. (1957). Studies of babies born at high altitude. I. Relation of altitude to birth weight. Am J Dis Child 93:666-669.

Lippl FJ, Neubauer S, Schipfer S, Lichter N, Tufman A, Otto B, and Fischer R. (2010). Hypobaric hypoxia causes body weight reduction in obese subjects. Obesity 18:675-681.

Llanos AJ, Ebensperger G, Herrera EA, Reyes RV, Pulgar VM, Seron-Ferre M, Diaz M, Parer JT, Giussani DA, Moraga FA, and Riquelme RA. (2011). Fetal and postnatal pulmonary circulation in the Alto Andino. Placenta 32: S100-103.

Marinoni E, Casciani V, Marianetti V, Di Rocco A, Moscarini M, and Di Iorio R. (2007). Localization and distribution of adrenomedullin receptor in the human placenta: Changes with gestational age. J Reprod Med 52:831-838.

Mihov D, Bogdanov N, Grenacher B, Gassmann M, Zund G, Bogdanova A, and Tavakoli R. (2009). Erythropoietin protects from reperfusion-induced myocardial injury by enhancing coronary endothelial nitric oxide production. Eur J CardioThor Surg 35:839-846; discussion 846.

Minamishima YA and Kaelin WG, Jr. (2010). Reactivation of hepatic EPO synthesis in mice after PHD loss. Science 329:407.

Moore LG, Charles SM, and Julian CG. (2011). Humans at high altitude: Hypoxia and fetal growth. Resp Physiol Neurobiol 178:181-190.

Moore LG, Hershey D, Jahnigen D, and Bowes W. (1982a). The incidence of pregnancy-induced hypertension is increased among Colorado residents at high altitude. Am J Obstet Gynecol 144: 423-429.

Moore LG, Rounds SS, Jahnigen D, Grover RF, and Reeves JT. (1982b). Infant birth weight is related to maternal arterial oxygenation at high altitude. J Appl Physiol Resp Environ Exercise Physiol 52:695-699.

Moraga FA, Reyes RV, Herrera EA, Riquelme RA, Ebensperger G, Pulgar VM, Parer JT, Giussani DA, and Llanos A.J. (2011). Role of the alpha-adrenergic system in femoral vascular reactivity in neonatal llamas and sheep: A comparative study between highland and lowland species. Am J PhysiolRegul Integ Comp Physiol 301:R1153-1160.

Nicola C, Chirpac A, Lala PK, and Chakraborty C. (2008). Roles of Rho guanosine 5'-triphosphatase A, Rho kinases, and extracellular signal regulated kinase $(1 / 2)$ in prostaglandin E2-mediated migration of first-trimester human extravillous trophoblast. Endocrinology 149:1243-1251.

Ockleford CD. (2010). The allo-epi-endothelial lining of the intervillous space. Placenta 31:1035-1042.

Palm F and Nordquist L. (2011). Renal oxidative stress, oxygenation, and hypertension. Am J Physiol Regul Integ Comp Physiol 301:R1229-1241.

Palmer SK, Moore LG, Berman JC, Cregger B, and Zamudio S. (1994). Altitude and hypertensive complications of pregnancy Am J Physical Anthropol 18:158.

Pappo O, Ben-Ari Z, Shevtsov E, Avlas O, Gassmann M, Ravid A, Cheporko Y, and Hochhauser E. (2010). The role of excessive versus acute administration of erythropoietin in attenuating hepatic ischemia-reperfusion injury. Can J Physiol Pharmacol 88:1130-1137.

Patel J, Landers K, Mortimer RH, and Richard K. (2010). Regulation of hypoxia inducible factors (HIF) in hypoxia and normoxia during placental development. Placenta 31:951-957.

Peng Y, Yang Z, Zhang H, Cui C, Qi X, Luo X, Tao X, Wu T, Ouzhuluobu Basang, Ciwangsangbu Danzengduojie, Chen $\mathrm{H}$,
Shi H, and Su B. (2011). Genetic variations in Tibetan populations and high-altitude adaptation at the Himalayas. Mol Biol Evol 28:1075-1081.

Pringle KG, Kind KL, Sferruzzi-Perri AN, Thompson JG, and Roberts CT. (2010). Beyond oxygen: Complex regulation and activity of hypoxia inducible factors in pregnancy. Human Reprod Update 16:415-431.

Quintero P, Milagro FI, Campion J, and Martinez JA. (2010). Impact of oxygen availability on body weight management. Med Hypotheses 74:901-907.

Qureshi IZ, Abid K, Ambreen F, and Qureshi AL. (2007). Angiotensin converting enzyme inhibitors impair recombinant human erythropoietin induced erythropoiesis in patients with chronic renal failure. Saudi Med J 28:193-196.

Rankin EB, Biju MP, Liu Q, Unger TL, Rha J, Johnson RS, Simon MC, Keith B, and Haase VH. (2007). Hypoxia-inducible factor2 (HIF-2) regulates hepatic erythropoietin in vivo. J Clin Investig 117:1068-1077.

Resch BE, Gaspar R, Sonkodi S, and Falkay G. (2003). Vasoactive effects of erythropoietin on human placental blood vessels in vitro. Am J Obstet Gynecol188:993-996.

Simon MC and Keith B. (2008). The role of oxygen availability in embryonic development and stem cell function. Nature Rev Mol Cell Biol 9:285-296.

Sommer N, Dietrich A, Schermuly RT, Ghofrani HA, Gudermann T, Schulz R, Seeger W, Grimminger F, and Weissmann N. (2008). Regulation of hypoxic pulmonary vasoconstriction: Basic mechanisms. Eur Resp J 32:1639-1651.

Stenmark KR, Fagan KA, and Frid MG. (2006). Hypoxia-induced pulmonary vascular remodeling: Cellular and molecular mechanisms. Circ Res 99:675-691.

Takeda K, Ho VC, Takeda H, Duan L-J, Nagy A, and Fong G-H. (2006). Placental but not heart defects are associated with elevated hypoxia-inducible factor alpha levels in mice lacking prolyl hydroxylase domain protein 2. Mol Cell Biol 26:83368346.

Teramo KA, Hiilesmaa VK, Schwartz R, Clemons GK, and Widness J.A. (2004). Amniotic fluid and cord plasma erythropoietin levels in pregnancies complicated by preeclampsia, pregnancy-induced hypertension and chronic hypertension. J Perinatal Med 32:240-247.

Tissot van Patot MC, Bendrick-Peart J, Beckey VE, Serkova N, and Zwerdlinger L. (2004). Greater vascularity, lowered HIF$1 /$ DNA binding, and elevated GSH as markers of adaptation to in vivo chronic hypoxia. Am J Physiol Lung Cell Mol Physiol 287:L525-L532.

Tissot van Patot MC and Gassmann M. (2011). Hypoxia: Adapting to high altitude by mutating EPAS-1, the gene encoding HIF-2a. High Alt Med Biol 12:157-167.

Tissot van Patot MC, Grilli A, Chapman P, Broad E, Tyson W, Heller DS, Zwerdlinger L, and Zamudio S. (2003). Remodelling of uteroplacental arteries is decreased in high altitude placentae. Placenta 24:326-335.

Tissot van Patot MC, Murray AJ, Beckey V, Cindrova-Davies T, Johns J, Zwerdlinger L, Jauniaux E, Burton GJ, and Serkova NJ. (2010). Human placental metabolic adaptation to chronic hypoxia, high altitude: Hypoxic preconditioning. Am J Physiol Regul Integ Comp Physiol 298:R166-172.

Trollmann R, Klingmuller K, Schild RL, Rascher W, and Dotsch J. (2007). Differential gene expression of somatotrophic and growth factors in response to in vivo hypoxia in human placenta. Am J Obstet Gynecol 197:601.e601-606.

Tuuli MG, Longtine MS, and Nelson DM. (2011). Review: Oxygen and trophoblast biology-A source of controversy. Placenta 32:S109-118. 
Wallukat G, Homuth V, Fischer T, Lindschau C, Horstkamp B, Jupner A, Baur E, Nissen E, Vetter K, Neichel D, Dudenhausen JW, Haller H, and Luft FC. (1999). Patients with preeclampsia develop agonistic autoantibodies against the angiotensin AT1 receptor. J Clin Investig 103:945-952.

Ward JPT and McMurtry IF. (2009). Mechanisms of hypoxic pulmonary vasoconstriction and their roles in pulmonary hypertension: New findings for an old problem. Curr Opin Pharmacol 9:287-296.

Westerterp KR, Kayser B, Brouns F, Herry JP, and Saris WHM. (1992). Energy expenditure climbing Mt. Everest. J Appl Physiol 73:1815-1819.

Whitley GSJ and Cartwright JE. (2010). Cellular and molecular regulation of spiral artery remodelling: Lessons from the cardiovascular field. Placenta 31:465-474.

Winkelmayer WC, Liu J, and Brookhart MA. (2009). Altitude and all-cause mortality in incident dialysis patients. JAMA 301:508-512.

Yung HW, Cox M, Tissot van Patot MC, and Burton G. (2012). Evidence of endoplasmic reticulum stress and adaptive protein synthesis inhibition in the high-altitude human placenta. FASEB J 26:1970-1981.
Yurovsky VV. (2003). Tumor necrosis factor-related apoptosisinducing ligand enhances collagen production by human lung fibroblasts. Am J Respir Cell Mol Biol 28:225-231.

Zamudio S, Torricos T, Fik E, Oyala M, Echalar L, Pullockaran J, Tutino E, Martin B, Belliappa S, Balanza E, and Illsley NP. (2010). Hypoglycemia and the origin of hypoxia-induced reduction in human fetal growth. PLoS ONE 5:e8551.

Address correspondence to: Dr. Martha C. Tissot van Patot Institute of Veterinary Physiology Vetsuisse Faculty and Zurich Center for Integrative Human Physiology (ZIHP)

University of Zürich

Winterthurerstrasse 260 CH-8057 Zürich Switzerland

E-mail: marthatissot@me.com

Received May 17, 2012; accepted in final form June 20, 2012. 